\title{
Effective Leadership Conducive to Generation of Academic Performance in Schools
}

\author{
Ololade Kazeem Shonubi (PhD) \\ Department of Education Leadership and Management, University of Johannesburg - South Africa \\ okshonubi@uj.ac.za
}

\section{Doi:10.5901/mjss.2014.v5n20p1868}

\section{Abstract}

The purpose of this paper was to understand and compare two schools in relation to how effective leadership functions (instructional and transformational leadership) may have been utilized to arrive at differential academic outputs in schools. Towards this end, an exceptionally performing and under-performing school was chosen from within the same socio-economic context with a view to understand how instructional and transformational leadership could result in generating optimal academic performance. These selected schools are government owned and thus, receive similar treatment in terms of funding, control, commitment, management and control, etc. Therefore a major research question: How do selected leadership functions bring about generation of differential student's exceptional academic performance in schools? Utilizing the qualitative research approach, data was collected from internal key role players (otherwise referred to School Leadership Team [SLT]) from two selected schools: one exceptional performing and the other, underperforming. Participants in the study are; Principals, Viceprincipals and Heads of Department (HODs) from the two schools. I utilised one-on-one semi-structured interview, observations and document review to obtain rich data towards providing answers to the puzzle of the study. Findings among others indicate that monitoring, modelling, and internally funded training and development of teachers, ensured effective instructional delivery and up-date of knowledge in the teaching skills; and subject knowledge update of teachers in the exceptionally performing school, which impacted on student's performance in the exceptionally performing school, compared to the exceptionally underperforming school.

Keywords: Transformational leadership, Instructional leadership, exceptional performing and underperforming, academic performance; and input and output variables.

\section{Introduction}

The purpose of this paper was to understand and compare how two effective leadership functions - instructional and transformational leadership - could be conducive to the generation of differential academic performance in two public secondary schools. These schools are located within similar context, as they are State owned; hence they enjoy similar treatment (funding, administrative monitoring and control, etc.), that is, equal levels of commitment and management from the government. Moreover, these schools possess similar structural and physical outlook in terms of school facilities, teaching and learning materials, which are adequately provided and well maintained. Moreover, both sampled schools are located within the same socio-economic environment (less than 5 Kilometres apart); and the School Leadership Teams (SLT) and teachers in both schools possess similar work experience and academic qualifications.

Literature on the relationship between effective school leadership and its possible impact on effective academic performance of students abounds (Earley and Weindly, 2004; Hallinger and Heck, 2010:149-147 and; Huber, 2004). Studies in literature have also pointed towards the need to explain factors contributing to effective academic performance in school, because the concept of effective academic performance often points to many visible and invisible variables (Mortimore, Sammons, Thomas, 1994:22). In essence, it suggests that effective academic performance points to "meansends" - (input-output) - variable relationship like, orderly atmosphere and a learning climate, setting instructional strategies, coordination of instructional programmes, supervising and supporting teachers, orientation towards educational development and innovation; and parental involvement towards the achievement of school's missionorientation and vision (Kruger, Witziers and Sleegers, 2007:1-20, Scheerens, 1992:37). Therefore, in this paper, students' academic performance specifically represents curricular output variable, and it is viewed in relationship with internal school leadership input variables.

The significance of the above functions of effective leaders implies that they possess the ability to bring about possible proficiency, professional judgments and responsible skills, which are imparted on teachers and towards the discharge of their duties in classrooms (Kyriakides, Demetrious and Charalambus, 2006:1-20). Therefore, the ability of a 
school to transform itself is to a great extent dependent on the quality of leadership (Davidoff and Lazarus, 1997:153154). The argument of this paper is that, instructional and transformational leadership are important characteristics which enhance effective academic performance of students (Leithwood and Duke, 1999; Kruger, Witziers and Sleegers, 2007:120). To this end, efforts of a school principal through leadership capacity may have significant bearing on the instructional transformation of teachers, which may impact on the performance of their tasks; more so, empirical studies indicate that instructional and transformational leadership are two of the foremost models in school leadership (Hallinger, 2003:329351, Sleegers, 2007:1-20). This has led to the generation of a main research question: "How do selected leadership functions bring about generation of differential student's academic performance in schools? Two sub-questions generated from the main research question are: (i) How does instructional leadership generate students' exceptional academic performance? (ii) How does transformational leadership generate students' exceptional academic performance? This study is significant, because SLT do not just impact on school milieu, but also on teachers' leadership approach of their' task in the classroom.

\section{Literature Review}

\subsection{Conceptualizing school leadership in relation to student academic output}

During the past decades, much attention has been paid to the meaning and importance of leadership. According to Bush (2007:391), great interest in educational leadership began in the early part of the $21^{\text {st }}$ century. This is because of the widespread held belief that, quality of leadership makes a significant difference to student's leaning performance. More so, Earley and Weindling (2004) maintain that "leadership at all levels in school should be judged by their effect on the quality and standards, despite that school leaders have a broad (some would say) and ever-burgeoning array of responsibilities". As a result, school leadership requires trained and committed teachers, highly effective principal's leadership and the support of other senior managers (Bush, 2007:391) within the internal school environment.

From the above, it may be deduced that leadership is basically concerned with goal achievement and the initiation of change through influence, power (knowledge or expertise, etc.), authority, directing, communicating, influencing and energizing of followers, towards maximizing the performance of school tasks (Davidoff and Lazarus (1997). The concept of leadership implies that an education leader must maintain a healthy balance between task-oriented and peopleoriented leadership style, in order to ensure teachers' accountability.

\subsection{Instructional leadership model}

Some school leaders are being developed for a central function. That is, the promotion of students' learning through instructional leadership (Bush, 2007:391-406). Instructional leadership is strongly concerned with teaching and learning, including professional learning of teachers, as well as students' growth. Khan, Ahmad, Ali and Ur-Rehman (2011:26682678) found that school principals are aware of the importance and value of providing professional support and motivation of teachers, based on their expectations of a high standard of instructional professionalism in return from the teachers. In that case, instructional leaders must follow the path of traditional leadership roles and are expected to be knowledgeable experts, serving as centres of institutional power. Such leaders tell the teachers "how and what" to teach. In the past, instructional leaders were source of knowledge. However today, the instructional leader might also be a source of direction and instruction (Leithwood and Duke, 1999).

Knowledge of questions stemming from 'what is and how' prompts a school instructional manager to promote positive school climate or hold an image or vision of 'what should' be accomplished in relation to instruction activities, in order to record a high and effective performance of teachers in the classroom (Greenfield, 1997). Therefore, it suggests that principals of schools must strive to promote academic excellence by giving prominence to academic achievers. In that case, the importance of the principal's role as an instructional leader and his/her direct relationship towards changing instructional practice to improve student performance and enabling formation of behaviour that is designed to affect classroom instruction, through the responsibility of informing teachers about new instructional strategies, technologies and tools that apply to effective instruction (Quinn, 2002:447-467).

\subsection{Transformational leadership model}

Transformational leadership assumes that the central focus of leadership ought to be concerned about the commitments and capacities of organisational members, whereby leaders and followers must achieve and become the best. This 
enables them to be united in the pursuit of higher-level common goals relevant for shaping the school in a certain direction (Leithwood et. al., 1999:9). Teachers' capacity development is usually achieved for example, when the principal sets challenging, but attainable goals for their staff, delegate responsibilities and authority; which in-turn positions staff development on high priority in the school (Gerber, et. al., 1998:262). Challenging goals enable teacher development to usually occur in the classroom, particularly through routine teaching experience. Anderson (2008:8-17) discusses the possibility of teachers being transformational in the classroom context and asserts that, "transformational leadership by teachers does exist in the classroom where effective teaching is practised". Although relatively modest in size, the body of empirical evidence about the effects of transformational leadership in the school context gives adequate and significant challenges for change, which necessitates greater accountability of the school leader (Day, Hall and Coles, 2000; Leithwood et. al., 1999). Therefore, Anderson (2008:8-17) concludes:

We have also learned that leadership is as much a property of the school and its culture, as it is a dimension of administrative roles. In the current teacher leadership scenario, it is not simply the principal that must be the instructional leader, but also teachers, by going wider and deeper: wider in extending their leadership to school-wide concerns and deeper in using this school-wide influence to increase teaching efficacy in the classroom.

In consistence with the above quote, Niemann and Kotze (2006:609-642) found that strong relationships appeared to exist between a principal's behaviour regarding the inspiration of a shared vision and attempts to enable staff members (including teachers) to act in cultivation of sociable element, as part of a school culture. In that case, the principal's wealth of shared experience with teachers will enhance such teacher's growth and development in his tasks of teaching. The above conceptualization of transformational leadership indicates that, it focuses on sheer capacitation and orientation of teachers towards their optimal teaching growth, hence effective performance of teaching tasks in the classroom.

\subsection{Theoretical stance}

The theoretical framework of this research is built on Prinsloo's (2009) leadership and management model (adapted), because it consists of contextual, multi-level and multi-factor internal variable factors such as, school leadership variables (instructional, transformational, moral, and visionary leadership), which may influence classroom's instruction, hence students' academic performance. Utilizing the leadership segment of the model, it enabled me to investigate how school selected leadership - instructional and transformational - may facilitate the creation of conducive teaching environment for teachers, hence influencing students' academic performance. Moreover, the model gives a holistic picture of educational leader's role in the school Prinsloo's (2009) and indicates how the inter-relationship of leadership variable may influence students' academic performance. In addition, it explains that education leadership have to be centrally concerned with the purpose or aim of a school, namely: ensuring quality teaching and learning through effective instructional and

Figure 1: Prinsloo's leadership and management model (2009) [adapted]

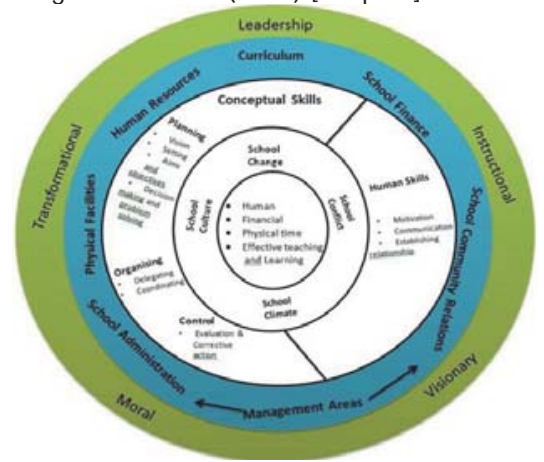

transformational leadership, etc. More so, the model acknowledges that the central role of educational leaders should be focused on the directing the actions and activities of teachers and; students and parents through other forms of school leadership dynamics (e.g., moral, instructional, transformational and visionary leadership, etc.). The Education Leadership Model is a brief summary of the leadership/management role and task required of the principal and other members of the SLT (University of Pretoria, 2010:38). Thus, it establishes that all the components of leadership model (transformational, instructional, visionary, moral leadership, etc.) must interact with effective and efficient human resources (teachers and others), financial resources and time on task (teaching and learning), in order to bring about effective performance of students (Prinsloo, 2009). 


\section{Research Design and Methods}

The qualitative approach to research was utilized; hence I believe that many realities exist, as reality is best understood from the perspective of the participant who experiences it (Nieuwenhuis, 2007:54) within a particular context. Therefore, the research was founded on the constructivist paradigm which is premised on participants' knowledge of reality - the knower and the known. In addition, towards understanding the phenomenon under study, I closely interacted with the participants' through interviews, and also observed occurrences in their natural settings in order to generate knowledge or answers to the research questions (Cresswell, 2012:259; Cohen, Manion and Morrison, 2007:115; and Lincoln and Guba, 1985). Moreover, case study research design was employed in this study. Two case cases of selected senior secondary schools each, provided in-depth insight into how instructional and transactional leadership functions influence students' exceptional performance and otherwise. Manion and Morrison (2007:254) suggest that case studies could be used to portray 'what it is like' to be in a particular situation, in order to grasp the close-up reality and the 'thick description of participants' lived experiences, thoughts about and feelings in a situation. (Cresswell: 2008:465).

Utilizing case study, the profile of the selected schools, such as: history of the schools, socio-economic environment of the schools, climate and culture of the schools, principals' previous experiences and qualifications, number of teachers in each school and their qualifications; student enrolment, teacher-student ratio and parental support was retrieved and analysed. Also, participants were selected based on purposive sampling, because "they constitute sample that satisfy the specific needs of the investigation" (Cohen, et. al., 2007:114-115). Thus, 3 participants (Principal, Vice-principal and HOD) were selected from each of the sampled schools, making a total of six participants in the study. Participants in each school have worked for more than five years, according to observed record indicating years of work experience in both schools.

The academic performance records for 5 consecutive years in English Language subject were extracted and verified through the national examination body known as, West African Examination Council (WAEC). The documents were specifically collected, compared and analysed amongst other subjects, because English Language is the only compulsory subject offered to every student; hence students must pass the subject before they could apply for any course of study in any Nigerian tertiary institution of learning. 5 years was deem fit for the basis of comparing the exceptional-performing and under-performing nature of the selected schools, because academic achievement consistency is fair, when effects (instructional and transactional leadership effects on students' academic performance, as in this paper) at the end of a period of schooling are examined over a relatively short-time interval (Scheerens, 1999:150).

Data gathering was done by utilizing semi-structured (one-on-one interviews), observation and document analysis of relevant school records. Moreover, the trustworthiness of data - criteria of 'credibility, transferability, dependability, confirmability' - was established through triangulation. Triangulation was utilized to determine points of similarities and differences between data collected through, prolonged interviews, observations and document analysis (Guba and Lincoln (2005:24). I obtained ethical clearance from my university to assure participants of voluntary participation, confidentiality and anonymity. Data analysis was through 'a priori' approach; therefore instructional and transformational leadership themes or categories were generated from the literature, as the categories of information required from the data are formulated in advance, thus, categories are distilled from the literature on the topic of study" [Nieuwenhuis, 2007:99].

\section{Data Analysis and Discussion (School A and B)}

This study explores effective school leadership conducive to generation of students' academic performance. The exceptionally performing and under-performing schools are labelled School A and B, respectively. The participants of school A, are labelled: Principal - P1; Vice-principal - Vp1; and Head of Department - HOD1; while School B participants are labelled, Principal - P2; Vice-principal - Vp2; and Head of Department - HOD2. The participants are all referred to School Leadership Team (SLT) members. Data analysis and discussion below show how instructional leadership and transformational leadership may be conducive to the generation of exceptional academic performance.

\section{Instructional Leadership Practice of SLT in School A and B}

School A Principal, Vice-principal and the HOD share similar comment on how they exercise instructional leadership. The philosophy which they all share concerning leadership was underscored, that is, 'leadership by example'. Hence the Principal made it known that he teaches one of the school subjects - Accounting - in order to prove his exemplary 
leadership. Quoting the principal:

"I go round to observe teaching in the classrooms and also try to reinforce good teaching attitude of the teachers; and look at their interpersonal relationship with students. I also teach one of the subjects. So, when they - teacher - see me doing that, they won't have a choice than to be morally upright in discharging their teaching duties appropriately" P1.

It is obvious from the above that the school principal shows concern for instructional efficiency, as he habitually supervises teaching in the school and model good teaching attitude, which indicates that he is usually visible in the school. The implication of the principal's action may be far reaching, as Brown and Anafara Jr. (2003:16-34) findings support principal's leadership behaviour, concerning school instructional supervision and confirms that it involves an initial exploration of possible change areas, discussions and education, regarding issues which involves support, commitment and ownership of teaching and learning. By implication, the enthusiasm of the principal in achieving School A's goal of effective teaching and learning, is through commitment towards the implementation of established school objectives and goals through "demonstration of high-performance expectations and the establishment of a productive school culture, is based on strong relationship between a principal's behaviour as regards an inspiration of a shared vision" (Niemann and Kotze (2006:609-642).

Still on instructional leadership practice in School A, the Vice-principal and HOD similarly commented on how they encourage teachers to meet them in their personal offices (Vice-principal and HOD's offices), where they - teachers - are taught about topics that are perceived difficult in their subjects curriculum. Quoting the words of the Vice-principal, She said:

"When some teachers find the teaching of some topics difficult, they report to me that they are finding some topics difficult to teach in their individual teaching subjects; I teach them, by telling them to meet me in my office, particularly when the topic is in my area of specialization" Vp1.

The HOD also makes it a necessity for teachers to meet him in his office, in order for instructional issues relating to teachers' misunderstanding in their various subjects to be discussed.

"I tell teachers to meet me in my office, so that I may put them through some topics that they do not really understand, especially if those topics fall within my area of knowledge" HOD 1.

The foregoing implies that School A Principal, Vice-principal and the HOD demonstrate qualities of leadership through coaching. Therefore School A SLT sets examples through 'best practice' which is also evident on their modelling and coaching efforts. I observed the SLT members' names in the school's teaching roster. However, I did not witness the school principal, teaching the students during my period of data collection, but the school Teaching Roster (TR) indicates the school SLT's names and subjects which they teach. Nevertheless, the HOD and the Vice-principal of the school were sighted and observed, as they taught the final years (final Grade) students.

Therefore, it may be concluded that the SLT of School A demonstrates elements of instructional leadership, as Khan, Ahmad, Ali and ur-Rehman (2011:2668-2678) report in their findings that school principals are aware of the importance and value of providing professional support and treatment for staff members, thus they - principals - expect a high standard of professionalism in return. Moreover, Bush and Glover (2002:10) stress that a school influence-process direction is directed towards instructional leadership, which focus on teaching and learning; and the behaviour of teachers when working with students. By implication, School A SLT influence is targeted at students' learning via teachers as, "emphasis is on the 'direction and the impact of influence', rather than the influence process itself". As a result, effective leaders implicitly work very carefully on their indirect effects, moreover that school leaders have an influence through three related strategies of modelling, monitoring and dialogue" (NCSL, 2004). This findings also corroborate Ofsted's (2003:20) revelation, which indicates a strong link between very good monitoring and better teaching, suggesting that "where monitoring is effective, the quality of teaching is noticeably higher compared to schools where monitoring is poor and infrequent".

In School B, instructional leadership is not practised in similar spirit, as it is in School A. School B's Vice-principal and HOD's comment indicate that their school principal is too busy in his office; hence he does always supervise instructions in the school. This is corroborated by the comment of the Principal when he said: "...however, I make sure that I sometimes send the vice-principal to go round to make sure that teachers are teaching in the classrooms" P2.

The comment of the principal presupposes that instructional leadership aspect of the school is not of primary importance. Evidently, I observed countable numbers of teachers supervising students during the compulsory extra-mural 
reading periods in School B. To this extent, the behaviour of School B Principal is contrary to Southworth's (2002:79) submission that, "instructional leadership is strongly concerned with teaching and learning. Hence, teachers must go to class regularly to teach and engage with the students whenever they go to the classroom to teach". Nevertheless, School B principal's influence is not targeted at student learning via the teachers, as his behaviour demonstrates lack of involvement, engagement and commitment in the management of purposive instructional programmes in the school (Bush and Glover (2002:10). From the above, it may be deduced that School B Principal's behaviour is contrary to a major characteristics of instructional leadership, which is, improving teaching and learning.

School B Vice-principal and HOD similarly established that they do not bother to oversee teachers' delivery of instructions, as they are 'fed-up' of teachers' inability to teach their subjects satisfactorily; which negatively affects students' understanding of what teachers teach, hence poor academic performance. The Vice-principal said: "I don't really care to bother myself to supervise the teachers, because there is no guarantee that the teachers will effectively complete all the topics to be taught under my supervision" Vp2. The HOD's comment also correspond the Vice-principal's view on instructional supervision of teachers as he said: "I don't interfere with teachers' supervision, because they have the freedom to handle their subject the way they deem and as a result, some of them do not complete their subject syllabus" HOD2.

Based on the analysis above, it appears that because School B Principal, Vice-principal and the HOD do not teach any of the school subjects, they do not care about supervising teachers' lesson delivery and this result into possible students and teachers' indiscipline towards and during the discharge of their teaching duties. Research also shows that teachers watch their leaders closely over time to test whether their actions are consistent with what they say through supervision, hence modelling best practice NCSL (2004). By inference, if an educational leader (e.g., principal) does not demonstrate leadership through supervision of teaching, such leader might not be respected by teachers. The fact that School B's SLT is not involved in the teaching of any of the school subjects may have discouraged the teachers to take instructional aspects of their jobs seriously.

In support of the above explanations, observed and analysed students' academic score-sheets indicate that the teachers do not promptly turn in students' examination results. In addition, there was no existing document to indicate that SLT members are involved in the teaching of any school subjects. An inference that could be made from the above analysis is that, there is little indication that School B Principal and other members of SLT complies with the criteria for instructional leadership. This is because little or no effort is made by the SLT to change teachers' instructional practice through well-planned teacher development strategies in the school.

\section{Transformational Leadership Practice of SLT in School A and B}

In School A, there is similarity in the expression of the principal, Vice-principal and the HOD, regarding the transformation of teachers. The principal stated that the school strives to upgrade its teachers through the attendance of workshops and seminars, so that they may be in touch with development in the subjects they teach. Hence, the SLT collectively invite skilled professionals to train teachers when development needs are identified. The principal emphasized that in-house workshops organized by SLT of the school are different from the conventional development workshops offered to schools by the government - Lagos State Ministry of Education (MoE). The principal made the following statement with respect to staff development:

\footnotetext{
"...we believe in... in-house training which we have been giving to our teachers at subject, departmental and administrative levels. We look at how a teacher has been performing in the classroom generally and train him or her about the new development in his or her area of specialization. We normally invite subject and curriculum specialists from outside the school to train our teaching staff so that they can keep up with the latest developments in education and we pay those experts from funds generated through our Parents-Teachers'-Association (PTA)" P1.
}

Observed official teacher training record indicates that teachers have experienced development workshop in the past up-to the time that the research is being conducted, as buttressed by the Principal's comment above. The above also indicates strong elements of transformational leadership practice by School A Principal. Through monitoring, collaboration with experts and quest for the update of teachers' professional knowledge, the principal seems to identify and acknowledge training areas and needs. Therefore, a possible inference that could be generated from this analysis is, the principal has concern for staff development which is aimed at improving teaching capacity. Capacity building was possible through the utilization of the funding generated by the PTA - school stakeholder - which indicates that the principal realizes that "the principle of enhancement and intellectual stimulation of teachers may ensure greater success 
and efficiency in the school" (Harms and Knobloch, 2005:101-124).

The action of the principal as it concerns monitoring of teachers' professional capacity is also confirmed by Eshbach and Henderson's (2010:16-48) conclusions that, "principals realize the important role that transformational leadership plays in effective management, capacity building and maintenance of the teachers' instructional leadership". Gerber, et. al. (1998) also indicate that transformation of teachers is usually done for example, when the principal sets challenging, but attainable goals for the staff, delegate responsibilities and authority; thus, making staff development a high priority through collaborations as indicated by the instructional practice of School A SLT.

Furthermore, School A HOD and Vice-principal made similar remarks on their transformational leadership activities. The Vice-principal said there were times when she organizes in-house training for the teachers, as a result of the related personal experiences that she gains through some of the instructional delivery conferences/workshops attended. In the words of the Vice-principal:

\begin{abstract}
"We identify teacher training needs through the last training records of teachers in the school and organize in-house training. If the principal or myself as the vice-principals have attended a seminar that may be connected to improvement of teaching, we organize what we call, in-house training for teachers"Vp1.

Comment of the HOD on his transformational leadership practice also bothers on the internal effort of the school SLT: "teachers are always developed internally by our school. The government does not always call for training development, except there is a special and important reason for doing that" HOD1.
\end{abstract}

From the above analysis, it is obvious that instructional leadership practice of School A SLT members seems to have bearing on the knowledge and teaching practise capacity of the teachers, which may have resulted in their effective teaching performance; hence students' effective academic performance. This is because the SLT of School A identifies with transformational leadership practice through the sharing of personal experiences, professional training and development with teachers. The SLT's behaviour towards transformational leadership also indicates team efforts towards achieving the goal of building teachers' capacity, which corroborates Niemann and Kotze (2006:609-642)'s findings that, "strong relationships appeared to exist between a principal's behaviour regarding the inspiration of a shared vision to transform teachers in the school".

Contrarily, interviews with School B SLT members reveal that it is the sole responsibility of the State government to develop teachers; hence they never make any effort to develop their teachers. The Principal and the Vice-principal similarly said: "Development of teachers is the sole responsibility of the government through the Ministry of Education $(\mathrm{MoE})$ and, that is the only means of teacher development that our school relies on" P2 and Vp2. No official document was shown to me to prove that it is the sole responsibility of the government to train teachers. Also, there was no official record indicating that in-house training of teachers has been conducted in the school, in the past years; hence it suggests that teachers have not been attending development workshops to update their subject skills.

Similar to the Principal and Vice-principal's comment, the HOD stated that:

"...the development of teachers however depends on the amount and availability of funds allocated by the government. For that reason, teacher development may be once in a year and in the past few years, teachers have not been called or invited for in-service training" HOD2.

The comment above indicates that School B SLT members do not make effort to generate funds to train teachers unlike School A, whose fund were gotten through PTA to develop and train teachers, even though they don't regularly get invites for training and development from the government. School B's SLT members do not teach a school curriculum subject, which may motivate teachers by way of modelling and that is one of the means of displaying 'leadership by example', so as to bring about coaching and mentorship of teachers. By implication, School B SLT's comment on transformational leadership is contrary to the submissions of Davidoff and Lazarus (1997:153-154), which confirm that the ability of schools to transform themselves is to a great extent dependent on the quality of leadership. It is therefore evident that School B does not make attempts to develop the teachers for better capacitation, through acquisition of instructional teaching practice skills and knowledge. In a similar disposition, Davidoff and Lazarus (1997:153-154) explain that "commitment to take responsibility frees one from making excuses, as to why a negative situation cannot change and allow someone to make a real difference in a situation". It is thus evident that School B SLT does not commit itself to capacity development of teachers, as it waits and expects the government to exclusively update and develop teachers.

The above reactions of School B principal, Vice-principal and HOD towards teacher development and training point to the behaviour of typical leaders who are not committed to building the knowledge capacity of teachers, which may subsequently affect students' academic performance negatively. It however indicates that School B SLT is neither "willing 
to take responsibility for building teachers' capacity nor enhance the intellectual stimulation of teachers to be successful" (Harms and Knobloch, 2005:101-124). If development and training of teachers are not emphasized, there may not be opportunities for intellectual stimulation for teachers to experience a greater sense of efficiency and success. Consequently, the SLT comment on inability to develop teachers may have been demotivating teachers to exhibit standardized knowledge practice, as far as teaching and learning is concerned.

\section{Implication and Conclusion}

The questions raised in this paper have significant theoretical and methodological implications. It focuses on the complex manner in which school leadership functions (transformational and instructional) may be exhibited by school SLT towards achieving limitless students' academic performance. The implication of this is that, schools may no longer wait for the government to finance every programmes that makes their schools to perform (as found in School B, in this study); therefore development of teacher may have to involve parents-community financial contributions. Secondly, findings of the paper points to the fact that school SLT members may participate in teaching some of the school's teaching subjects, despite the administrative 'load' of tasks that they are engaged. This will enable the teachers to be coached, motivated, encouraged and challenged to effectively execute their routine tasks as prescribed by school rules; because evidence suggests that "the effort required for a school to move in the direction of empowerment and shared leadership does not occur easily, as many study point to teacher's reluctance to participate in leading" (Hallinger, 2003:329-351).

In conclusion, this study draws attention towards understanding how effective leadership could be conducive to the generation of extreme academic performance in schools located within similar context. The findings in this study contribute to the mounting evidence on the influence of internal school leadership, which is based on through mentoring, coaching; and development of teachers' capacity towards influencing students' academic performance, etc. It also assumes that financial resources provided by parents to develop teachers may have been contributing to teachers' professional development; hence self-confidence in their individual teaching subject, which influences teaching and learning, etc. That may further have bearing on 'classroom level' time on task, structured teaching, students' preparedness to learn new things through the teachers, enhance school principals' degree of evaluation and monitoring of students' progress, hence reinforcement of their learning. Collaboration with parents to develop teachers had enabled School A SLT (exceptionally performing school) to position teachers who may have been willingly exhibiting effective instructional teaching practice in contrast to School B.

In summary, the synthesis of findings reveal that effective instructional leadership practice of School A SLT may have further enhanced teachers' transformational teaching practice in the classroom, respect for constituted authorities and policies by internal stake-holders (students, teachers and SLT members); self-respect and dignity, collective responsibility, and goal setting, hence students' exceptional academic performance. Additionally, this study demonstrates that effective school leadership has to do with the concern for staff development towards building teaching capacity of staff; and emphasis on the quality of instructional programme in the school, based on values of respect, accountability, truthfulness, fairness and honesty, culminating to quality teaching and learning. More so, the study indicates that professional face-lift given to teachers may successfully be instrumental to upgrading their professional capacity towards exhibiting 'best' instructional practice in classroom (in terms of knowledge delivery), towards exceptional academic performance of students.

\section{Limitations}

This study is limited to a comparative case-study sample of two schools (One exceptionally performing and underperforming school each), drawn from a similar socio-economic education district in Lagos State - Nigeria. Based on record document, these schools obviously indicate most exceptional performance and underperformance among the schools located with the particular education district and socio-economic environment in which they are both located. However, I acknowledges that two functions of leadership (instructional and transformational) may not solely provide conclusive answers as to the reasons for students' academic performance, but believes that this research may provide some valuable clues for further research on students' exceptional academic performance and underperformance of schools located within similar context. Thus, I accept that other functions of leadership may also contribute to exceptional academic performance of students, e.g., parental involvement, self-discipline and motivation of students, etc. 


\section{References}

Anderson, K. D. (2008). Transformational leadership in rural schools. The Rural Educator, Spring, 29 (3), 8-17.

Brown, M. K. and Anafara Jr. V. A. (2003).Paving the Way for Change: Visionary leadership in action. NASSP Bulletin, 87 (653), 16-34.

Buckridge, M. and Guest, R. (2007).A conversation about pedagogical response to increased diversity in university classrooms.Higher Education Research and Development, 26 (2), 133-14

Bush, T. (2007). Education Leadership and Management: Theory, policy and practice. South African Journal of Education, 27 (3), $391-$ 406.

Bush, T. and Glover, D. (2002).School leadership: Concepts and Evidence. Nottingham: National College for School Leadership.

Cohen, L., Mannion, L. and Morrison, K. (2007).Research Methods in Education (6th ed.). Routledge: London.

Cresswell, J. W. (2012). Educational research: Planning, conducting and evaluating quantitative and qualitative research (2nded.). Upper Saddle River, NJ: Merrill/Prentice Hall.

Davidoff, S. and Lazarus, S. (1997). The Learning School: An organizational development approach: Cape Town:Juta.

Day, C. C., Hall, P. G and Coles, M. (1993).Leadership and Curriculum in the Primary School: The Roles of senior and middle management. London: Paul Chapman.

Earley, P. and Weindling, D. (2004).Understanding School Leadership.London; Paul Chapman.

Eshbach, E. C. and Henderson, J. E. (2010). The symbolic relationship between new principals and the climate of schools which they lead. e-Journal of Organizational Learning and Leadership, 8 (1), 16-48.

Gerber, P. D., Nel. P. S and Van Dyk, P. S. (1998). Human resources Management, Johannesburg: Thompson.

Greenfield, W. (1997). Instructional Leadership: concepts, issues and controversies. Boston: Allyn and Bacon.

Guba E. G. and Lincoln, Y. S. (2005).Competing paradigms in qualitative research.In Denzin, N.K and Lincoln, Y (Eds.) (1994), Handbook of Qualitative Research.Sage publications, p.107-108.

Harms, B. M. and Knobloch, N. A. (2005). Pre-service teachers' motivation and leadership behaviour related career. Career and Technical Education Research, 30 (2), 101-124.

Hallinger, P. and Heck, R. H. (2010). Conceptual and methodological issues in studying school leadership effects as a reciprocal process. School Effectiveness and School Improvement, 22 (2), 149-173.

Huber, S. G. (2004). Preparing Leaders for the 21st Century: An International Comparison of Development Programs in Fifteen Countries. London: Taylor and Francis.

Hallinger, P (2003). Leading educational change: reflections on the practice of instructional and transformational leadership. Cambridge Journal of Education, 33 (3), 329-351

Kyriakides, L., Demetrious, D. and Charalambous, C. (2006).Generating criteria for evaluating teachers through teacher effectiveness research.Educational Research, 48 (1), 1-20.

Kruger, M. C., Witziers, B. and Sleegers, P. (2007). The impact of school leadership on school leadership on level factors: Validation of causal model. School Effectiveness and School Improvement, 18 (1), 1-20.

Khan, M. F., Ahmad, S., Ali, I and urRehman, F. (2011).The impact of School management trainings and principals attitude on students' learning outcomes.African Journal of Business Management, 5 (7), 2668-2678.

Leithwood, K. and Duke, D. L. (1999).A Century's quest to understand school leadership.In Murphy, J and Louis, K.S (Eds.).Handbook of Research in Educational Administration (2nd ed., pp. 45-72), San Francisco: Jossy-Bass.

Mortimore, P., Sammons, P. and Thomas, S. (1994). School effectiveness and value added measures. Assessment in Education, 1 (3), 315-332.

Murphy, L. (2005). Transformational leadership: a cascading chain reaction Journal of Nursing Management, 13 (2), pp.128-136.

NCSL (2004). Meeting the Challenge: Growing Tomorrow's School Leaders - a practical guide for school leaders, Nottingham, NCSL.

Niemann, R. Kotze, T. (2006). The Relationship between Leadership Practices and Organizational Culture: An educational management perspective. South African Journal of Education, 26 (4), 609-624.

Nieuwenhuis, J. (2007). Qualitative Research Design and Data Gathering.In Maree, K (2007).First Step in Research. Pretoria: Van Schaik Publishers.

Office of Standards in Education [Ofsted] (2003).Leadership and Management: What Inspection Tells Us. June. Crown Copyright.

Prinsloo, I. J. (2009). Leadership and management of learning in education: A Study Guide (LBL) 880 for M.Ed Leadership. Department of Education Management and Policy Studies, Pretoria: University of Pretoria.

Quinn, D. M. (2002).The impact of principals' leadership behaviors on instructional practice and student engagement.Journal of Educational Administration 40 (5), 447-467.

Sheerens, J. (1992). Effective Schooling Research: Theory and practice. London: Cassell.

Scheerens, J. (1999). School Effectiveness in Developing Countries: A review of the research evidence. University of Twente/World Bank, June, 1-50.

Southworth, G. (2004). Learning-centered leadership. In. Davies, B (Ed.). The Essentials of School Leadership. London: Paul Chapman and Cowin Press.

University of Pretoria (2010).Education Management 1: Pretoria: Distance Education Unit.

University of Pretoria (2010). Education Management 1: Pretoria: Distance Education Unit.

Van de Grift, W. J. C. M and Houtveen, A .A. M. (2006). Under-performance in primary schools.School Effectiveness and School Effectiveness and Improvement, 17 (3), 255-273. 